\title{
PENDAPATAN DAN RISIKO PENDAPATAN USAHA TANI PADI DAERAH IRIGASI DAN NON IRIGASI DI KABUPATEN BANJAR KALIMANTAN SELATAN
}

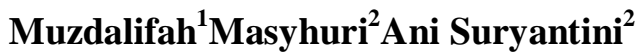

${ }^{1}$ Program Studi Sosial Ekonomi Pertanian Fakultas Pertanian Universitas Lambung Mangkurat

${ }^{2}$ Program Pasca Sarjana Fakultas Pertanian

Universitas Gadjah mada

\begin{abstract}
This study aims to determine the income and revenue risk from rice farming in irrigated and non irrigated land are also factors that influence it. The hypothesis advanced is that (1) factors that affect revenue and revenue risk rice farming in paddy fields are irrigated and non irrigated land area, the price of seed, fertilizer prices, wage labor, the price of seeds, irrigation areas and varieties, (2) rice farm income risk in irrigated land is lower than non-irrigated land. Data obtained through interviews with 80 randomly simple rice farmers. The method used is multiple linear regression analysis model with Ordinary Least Square (OLS) and the analytical coefficient of variation (CV). The results showed that the area of land, the price of urea, ponska price, the price of pesticides, and irrigation area dummy effect on income. While the risk is influenced by the land revenue, the price of seed, the price of urea fertilizer, fertilizer prices ponska, pesticide pricing and superior varieties of variables. Income risk in the area of irrigated rice farming was smaller than non-irrigated areas with kofisien variation of 0.83 and 0.89 .
\end{abstract}

Key words: revenue, risk, rice, irrigated and non irrigated area. 


\section{PENDAHULUAN}

Sektor pertanian di kabupaten Banjar mempunyai peran yang sangat penting dalam perekonomian daerah karena besarnya jumlah tenaga kerja yang terserap dan besarnya luas lahan yang digunakan dalam sektor pertanian. Di tengah-tengah upaya pemerintah dalam memperkuat perekonomian akibat krisis apakah usaha tani padi masih dapat diandalkan potensinya untuk mengatasi persolan-persoalan yang berkaitan dengan upaya meningkatkan laju pertumbuhan ekonomi, mengatasi pengangguran, dan meningkatkan pendapatan masyarakat. Sementara kontribusi sektor ini terhadap pendapatan daerah terus menurun yang secara tidak langsung menunjukkan semakin melemahnya motivasi petani untuk mengembangkan usaha tani, jika terus dibiarkan bukan tidak mungkin dapat mengancaman ketahanan pangan.

Dalam rangka peningkatan produksi pertanian di Kalimantan Selatan khususnya di kabupaten Banjar telah ada proyek irigasi yaitu irigasi Riam kanan atas bantuan pemerintah Jepang yang telah beroperasi sejak tahun 1992. Namun demikian di kabupaten Banjar masih banyak terdapat masalah pada daerah irigasi yang menyebabkan petani mengalami kegagalan panen atau tanaman menjadi kurang produktif

$$
\text { Berdasarkan latar }
$$

belakang dan uraian diatas, tentang pentingnya mengetahui pendapatan dan risiko pendapatan usahatani padi sebagai pertimbangan bagi petani dalam melakukan usahataninya, maka penelitian ini secara khusus bertujuan untuk (1). Faktor apa yang mempengaruhi pendapatan usahatani padi; (2).Berapa besarnya risiko pendapatan usahatani padi pada daerah irigasi dan non irigasi;

\section{LANDASAN TEORI}

\section{Teori Pendapatan}

Pendapatan bersih petani berupa jumlah produksi dikalikan harga dikurangi dengan biaya produksi dan pemasaran (Mubyarto, 1997). Hasil produksi (output) dilambangkan sebagai y dan faktor produksi (input) a dalah $\mathrm{x}$, sehingga terdapat hubungan antara input dan output yang dalam rumus matematikanya $\mathrm{y}=$ $\mathrm{f}\left(\mathrm{x}_{1}, \mathrm{x}_{2}, \quad \mathrm{xi} \quad \ldots . \mathrm{x}_{1} \mathrm{xn}\right)$, di mana $x_{1}, x_{2}, x_{i}$ dan $x_{n}$ dapat berupa lahan pertanian, tenaga kerja, modal dan manajemen (Soekartawi, 1990).

\section{Untuk}

mengidentifikasi faktor-faktor yang mempengaruhi pendapatan usahatani dapat dianalisis dengan fungsi keuntungan. Persamaan fungsi keuntungan diturunkan dari persamaan fungsi produksi. Persamaan fungsi produksi dapat dituliskan sebagai berikut :

$$
Q=A f(X, Z)
$$

Dimana :

$\mathrm{Q}=$ produksi

$\mathrm{A}=$ Besaran yang menujukkan tingkat efisiensi teknik

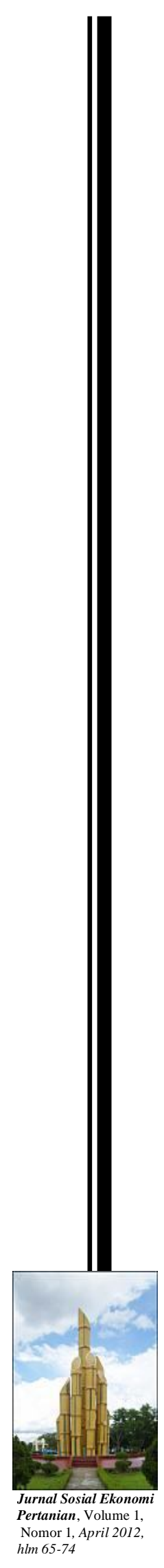




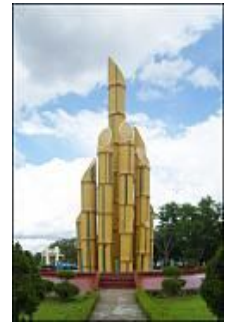

muzdalifah,masyhuri, suryantini pendapatan dan risiko usaha tani padi
$\mathrm{X}=$ variabel faktor produksi

$\mathrm{Z}=$ variabel faktor produksi tetap (fixed variabel)

Penggunaan persamaan

diatas berlaku asumsi bahwa dalam jangka waktu pendek, faktor produksi tetap seperti luas lahan dan alat-alat pertanian tidak mempengaruhi keinginan untuk meningkatkan keuntungan. Maksudnya, untuk setiap luas lahan tertentu petani dapat meningkatkan keuntungan dengan memanipulasikan harga dari faktor produksi tetap saja. Dengan demikian, maka persamaan keuntungan dapat ditulis (Yotopoulus dan Nugent, 1976)

$$
\begin{gathered}
\pi=p f(X i, \ldots, X m: Z j, \\
\ldots, Z n)-\sum_{i=1}^{m} v i X i
\end{gathered}
$$

Dimana :

$\Pi=$ keuntungan jangka pendek

$\mathrm{P}=$ harga output

$\mathrm{Xi}=$ input variabel

$\mathrm{Zj}=$ input tetap

$\mathrm{Vi}=$ harga input variabel $\mathrm{ke}-\mathrm{i}$

Keuntungan maksimum

tercapai pada saat nilai produk marginal sama dengan input (marginal factor cost). Secara matematik dapat dirumuskan dengan penentuan faktor produksi yang mempengaruhi produktivitas :

$$
\underset{\mathrm{i}=1,2,3, \ldots, \mathrm{m}}{p}=v i
$$

Dengan menyatakan $\mathrm{ci}=$ $\mathrm{ci} / \mathrm{p}$ sebagai harga input ke-i yang dinormalkan, maka persamaan dapat dituliskan sebagai berikut : $\begin{array}{ll}\stackrel{\partial f}{\partial x i} & = \\ \mathrm{i}=1,2,3, \ldots, \mathrm{m} \\ \text { Dengan }\end{array}$ persamaan, maka persamaanya menjadi :

$$
\pi^{*}=\frac{\pi}{p}=f(X i, \ldots, X m,:
$$

$Z j, Z n)-\sum_{i=1}^{m} v i X i *$

Dimana :

$\Pi^{*} \quad=$ keuntungan yang dinormalkan

Persamaan dapat memecahkan kuantitas optimal input variabel, yang dinyatakan sebagai Xi*, yaitu sebagai fungsi harga input variabel

$X^{*}=f i(v, Z)$

Dengan mensubsitusi persamaan, fungsi keuntungan menjadi :

$$
\begin{aligned}
& \pi=\operatorname{pf}\left(\mathrm{Xi}^{*}, \ldots, \mathrm{Xm}^{*}: \mathrm{Zj},\right. \\
& \ldots, \mathrm{Zn})-\sum_{i=1}^{m} v i X i * \\
& \pi=G\left(\mathrm{p}, \mathrm{vi}, \ldots, \mathrm{v}_{\mathrm{m}} ; \mathrm{Z}_{\mathrm{j}}, \ldots\right. \\
& \left., \mathrm{z}_{\mathrm{n}}\right)
\end{aligned}
$$

Fungsi keuntungan memberikan nilai maksimum keuntungan untuk setiap set nilai (P, c', Z). Dengan melihat pada persamaan selanjutnya ditulis :

$$
\begin{aligned}
& \quad \pi=\mathrm{PG}^{*}(\mathrm{vi} ; \mathrm{zj}) \\
& \text { Fungsi }{ }_{\text {keuntungan }} \text { yang } \\
& \text { dinormalkan menjadi : } \\
& \pi=\frac{\pi}{p}=\mathrm{f}(\mathrm{Xi}, \ldots, \mathrm{Xm}: \mathrm{Zj}, . .,
\end{aligned}
$$
$\mathrm{Zn)}$

Bila diasumsikan hubungan antara faktor produksi dengan produksi merupakan fungsi produksi Cobb-Douglas, maka fungsi keuntungan yang dinormalkan ditulis:

$$
\pi *=A * \pi(v i)^{\alpha i} \pi(Z i)^{\beta i}
$$

Dalam bentuk logaritma natural, persamaan ini dapat ditulis :

$$
\operatorname{Ln} \pi *=\ln A *+\sum
$$$$
\alpha i * \ln v i *+\sum \beta i * \ln Z i
$$ 


\section{Teori Risiko}

Menurut Siregar dalam Soekartawi (1993), risiko dalam pertanian mencakup kemungkinan kerugian dan keuntungan dimana tingkat risiko tersebut ditentukan sebelum suatu tindakan diambil berdasarkan ekspektasi atau perkiraan petani sebagai pengambil keputusan.

Menurut Pappas dan Hirschey (2005), risiko dapat diukur dengan menentukan kerapatan distribusi probabilitas. Salah satu ukurannya adalah dengan menggunakan deviasi standar yang diberi simbol $\boldsymbol{\sigma}$ (sigma). Semakin kecil deviasi standar, semakin rapat distribusi probabilitas dan dengan demikian semakin rendah risikonya.

Namun dalam penggunaannya terdapat beberapa masalah ketika standar deviasi digunakan sebagai ukuran risiko. Misalnya jika suatu usahatani memiliki biaya lebih besar, usahatani tersebut dapat secara normal memiliki standar deviasi yang lebih besar tanpa perlu menjadi lebih berisiko. Untuk mengatasi masalah tersebut adalah dengan menghitung ukuran risiko relatif dengan membagi standar deviasi dengan nilai rata-ratanya :

$$
\mathrm{CV}=\frac{\sigma}{E}
$$

Dimana :

CV : koefisien variasi $\sigma \quad$ : standar deviasi

E : rata-ratahasil (mean)

\section{METODE PENELITIAN}

Jenis data yang digunakan dalam penelitian ini adalah data primer dan data skunder. Data primer adalah data yang langsung dikumpulkan dari petani sebagai responden. Data yang digunakan meliputi produksi padi, luas lahan, harga pestisida, harga pupuk,upah buruh tani, dan harga jual. Sedangkan data skunder adalah data-data yang diperoleh dari pihakpihak terkait di daerah penelitian.

Daerah penelitian ditentukan secara purposive yaitu Kecamatan Sei Tabuk dan Kecamatan Gambut di Kabupaten Banjar. Dari dua kecamatan tersebut dipilih empat desa secara purposive, yaitu dua desa di daerah irigasi dan dua desa di daerah non irigasi. Sampel dipilih Secara proposional random sampling yang diambil sebanyak 80 sampel yang terdiri dari 40 sampel didaerah irigasi dan 40 sampel berikutnya di desa yang tidak termasuk daerah irigasi.

\section{Analisis Faktor-faktor yang mempengaruhi pendapatan usahatani padi}

Untuk mengetahui faktorfaktor yang mempengaruhi pendapatan pada usahatani padi digunakan model fungsi pendapatan yang diturunkan dari fungsi CobbDouglss. Dirumuskan dengan persamaan sebagai berikut :

$$
\begin{array}{r}
\operatorname{Ln}_{i}=\operatorname{Ln} \alpha o+\alpha_{1} \ln X_{1+\alpha} \\
{ }_{2} \ln X_{2}+\alpha{ }_{3} \ln X_{3}+\alpha \\
{ }_{4} \ln X_{4}+\alpha{ }_{5} \ln X_{5}+\alpha
\end{array}
$$

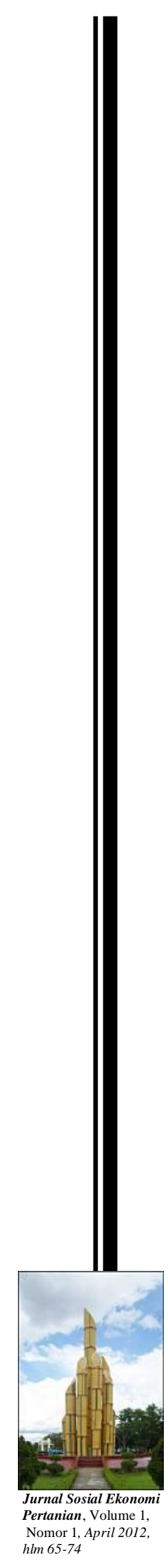




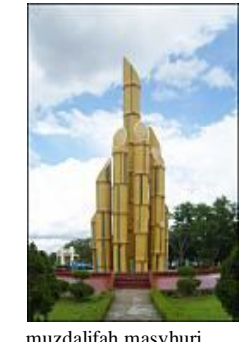

suryantini pendapatan dan risiko usaha tani padi

$$
\begin{aligned}
& { }_{6} \ln X_{6}+\alpha \quad{ }_{7} \ln X_{7}+\delta \\
& { }_{8} D_{1}+\delta_{9} D_{2}+e
\end{aligned}
$$

\section{Analisis}

risiko pendapatan usahatani padi pada lahan sawah non irigasi dan lahan sawah irigasi

Risiko produksi dan risiko pendapatan dianalisis dengan menggunakan koefoisien variasi $(\mathrm{CV})$. Koefisien variasi (CV) merupakan ukuran resiko relatif yang diperoleh dengan membagi standar deviasi dengan nilai yang diharapkan (Pappas dan Hirschey,1995). Secara matematis risiko dirumuskan sebagai berikut:

$\mathrm{CV}=\frac{\sigma}{\overline{\mathrm{Y}}}$

Keterangan :

$$
\begin{aligned}
& \mathrm{CV}=\text { koefisien variasi } \\
& \sigma=\text { standar deviasi } \\
& \mathrm{Y}=\text { rata-rata pendapatan }(\mathrm{Rp})
\end{aligned}
$$

\section{Analisis Faktor-faktor yang mempengaruhi risiko pendapatan usahatani padi}

Untuk mengetahui faktorfaktor yang mempengaruhi risiko pendapatan usahatani padi digunakan varian dari pendapatannya maka digunakan fungsi varian dari pendapatanya, dan diformulasikan sebagai berikut

$$
\begin{array}{rlr}
\operatorname{Lne}_{\pi}^{2} & =\operatorname{Ln} \beta o+\beta_{1} \ln X_{1}+\beta \\
& { }_{2} \ln X_{2}+\beta{ }_{3} & \ln X_{3}+\beta \\
& \ln X_{4}+\beta & { }_{5} \ln X_{5}+\beta \\
& { }_{6} \ln X_{6}+\beta & { }_{7} \ln X_{7}+\delta \\
& { }_{8} \ln D_{1}+\delta{ }_{9} \ln _{2}+e
\end{array}
$$

$e^{2} \pi \quad:$

residual yang mencerminkan risiko pendapatan usahatani padi

$\mathrm{X}_{1} \quad$ : luas lahan (ha)

$\mathrm{H}_{2} \quad$ : harga benih yang dinormalkan dengan harga outputnya $(\mathrm{Rp} / \mathrm{kg})$

$\mathrm{X}_{3} \quad$ : harga input pupuk Urea yang dinormalkan dengan harga outputnya $(\mathrm{Rp} / \mathrm{kg})$

$\mathrm{X}_{4}$ : harga input pupuk KCL yang dinormalkan dengan harga outputnya(Rp/kg)

$\mathrm{X}_{5}$ : harga input pupuk ponska yang dinormalkan dengan harga outputnya(Rp/kg)

$\mathrm{X}_{6} \quad$ : harga input pestisida yang dinormalkan dengan harga outputnya (Rp/liter)

$\mathrm{X}_{7} \quad$ : Upah tenaga kerja yang dinormalkan dengan harga outputnya (Rp/HOK)

$\mathrm{D}_{1} \quad$ : dummy daerah irigasi

1 : daerah irigasi

0 : lainnya

$\mathrm{D}_{2} \quad$ : dummy varitas

1 : unggul

0 : lainnya

$\beta_{i} \quad$ : parameter yang diestimasi

$i \quad: 1 \ldots 11$

$\beta_{0} \quad$ : konstanta

e : error term

Dimana : 


\section{HASIL PENELITIAN}

\section{Faktor-Faktor Yang Mempengaruhi Pendapatan}

Dalam analisis faktor-faktor yang mempengaruhi pendapatan usahatani padi digunakan metode Ordianry Least Square (OLS) dengan variebl independen yaitu luas lahan, harga benih, harga pupuk urea, harga pupuk KCL, harga pupuk ponska, harga pestisida dan upah tenaga kerja. Semua variabel, kecuali luas lahan dinormalkan dengan harga outputnya.

Hasil analisis regresi faktorfaktor yang mempengaruhi pendapatan ditampilakan pada tabel 1 berikut:

Tabel 1 Faktor-Faktor Yang Mempengaruhi Pendapatan Usahatani padi di Kabupaten Banjar

\begin{tabular}{|c|c|c|c|}
\hline \multicolumn{4}{|c|}{ Variabel dependen (I) : Pendapatan } \\
\hline Variabel $(\mathbf{X})$ & Koefisien & t-statistik & Prob. \\
\hline Konstanta (C) & $1,569462^{* * *}$ & 8,602149 & 0,0000 \\
\hline Ln Luas lahan (X1) & $0,082169^{* * * *}$ & 3,441228 & 0,0010 \\
\hline Ln harga benih(X2) & $-0,003894$ & $-0,364244$ & 0,7168 \\
\hline Ln harga Urea (X3) & $-0,110249 * * *$ & $-3,525946$ & 0,0007 \\
\hline Ln Harga KCL (X4) & 0,021109 & 0,811498 & 0,4198 \\
\hline Ln Harga Ponska (X5) & $-0,031571^{*}$ & $-1,506733$ & 0,0956 \\
\hline Ln Harga Pestisida (X6 & $-0,021194 *$ & -1.806691 & 0,0751 \\
\hline Ln Harga TK (X7) & $-0,046350$ & $-1,234997$ & 0,2210 \\
\hline Daerah Irigasi (D1) & $0,027327^{*}$ & 1,571131 & 0,0912 \\
\hline Varitas Unggul (D2) & 0.011358 & 0,488437 & 0,6268 \\
\hline R-Square & 0,749502 & & \\
\hline Adjusted R-squared & 0,717296 & & \\
\hline S.E. of regression & 0,050024 & & \\
\hline F-statistic & 23,27154 & & \\
\hline
\end{tabular}

Sumber : Analisis data Primer

Catatan : $* * *=$ Signifikansi pada tingkat kepercayaan $99 \%$

$$
\begin{aligned}
& * * \quad=\text { Signifikansi pada tingkat kepercayaan } 95 \% \\
& * \quad=\text { Signifikansi pada tingkat kepercayaan } 90 \%
\end{aligned}
$$

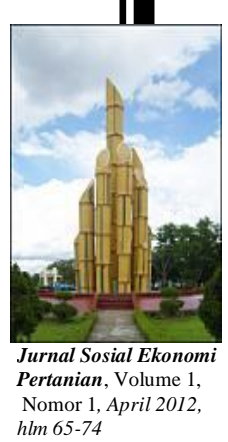




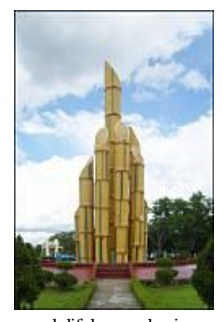

muzdalifah,masyhuri, suryantini pendapatan da risiko usaha tani padi
Hasil analisis regresi faktor-faktor yang mempengaruhi pendapatan menunjukan bahwa variabel- variabel independen yang berpengaruh nyata pada variabel dependen yaitu luas lahan, harga urea, harga ponska, harga pestisida, dan dummy daerah irigasi.

\section{Analisis Risiko pendapatan usahatani padi}

Untuk mengetahui besarnya risiko pendapatan yang dihadapi petani di daerah irigasi dan non irigasi juga digunakan analisis standar deviasi dan koefisien variasi. Tabel 2 berikut menunjukan perbedaan risiko pendapatan yang dihadapi petani daerah irigasi dan non irigasi

Tabel 2. Perbandingan Risiko pendapatan Pada Usahatani Padi di Kabupaten Banjar

\begin{tabular}{|l|r|r|}
\hline \multirow{2}{*}{\multicolumn{1}{|c|}{ Uraian }} & \multicolumn{2}{c|}{ Pendapatan Usahatani Padi } \\
\cline { 2 - 3 } & \multicolumn{1}{|c|}{ Daerah Irigasi } & Daerah non Irigasi \\
\hline Rata-rata pendapatan & Rp 4.356.216 & Rp.4.312.562 \\
\hline Standar Deviasi & 4760643,19 & 4595794,89 \\
\hline Koefisien Variasi (CV) & 0,83 & 0,89 \\
\hline CV $(\%)$ & 83 & 89 \\
\hline
\end{tabular}

Sumber :Analisis data Primer

Dari hasil analisis risiko pendapatan seperti disajikan pada tabel 2 menunjukkan bahwa risiko pendapatan sawah non irigasi lebih besar dari pada pendapatan sawah irigasi, yang diindikasikan dengan koefisien variasi pendapatan yang lebih tinggi pada petani non irigasi.

\section{Analisis Faktor-Faktor Yang Mempengaruhi Risiko Pendapatan}

Untuk menganalisis faktorfaktor yang mempengaruhi risiko pendapatan usahatani padi dilakukan terlebih dahulu dengan analisis regresi faktor-faktor yang mempengaruhi pendapatan selanjutnya residual dari analisis tersebut di analisis regresi kembali dengan variabel bebas yang sama.
Dari analisis yang dilakukan diperoleh hasil yang ditampilkan pada tabel 3 berikut : 
Tabel. 3 Faktor-Faktor Yang Mempengaruhi Risiko Pendapatan Usahatani padi di Kabupaten Banjar

\begin{tabular}{|c|c|c|c|}
\hline \multicolumn{4}{|c|}{ Variabel dependen $\left(\operatorname{Resid}^{\wedge}\right)$ : Risiko Pendapatan } \\
\hline Variabel & Koefisien & t-statistik & Prob. \\
\hline Konstanta(C) & $7,544293^{*}$ & $1 ., 606629$ & 0,0922 \\
\hline Ln Luas lahan $(\mathrm{X} 1)$ & $2,162959^{* *}$ & 2,224740 & 0,0293 \\
\hline Ln Harga benih(X2) & $0,868098^{* * *}$ & 2,833662 & 0,0060 \\
\hline Ln Harga Urea (X3) & $-25,59310$ & $-1,552114$ & 0,1251 \\
\hline Ln Harga KCL (X4) & 3,575731 & 0,191483 & 0,8487 \\
\hline Ln Harga Ponska (X5) & $18,56862 * * *$ & 2,752005 & 0,0075 \\
\hline Ln Harga Pestisida (X6 & $0,845231^{*}$ & 1,991430 & 0,0503 \\
\hline Ln Harga TK (X7) & 0,797883 & 0,547355 & 0,5859 \\
\hline Daerah Irigasi(D1) & 0,150419 & 0,227458 & 0,8207 \\
\hline Varitas Unggul (D2) & $-2,716262^{* *}$ & $-2,976933$ & 0,0040 \\
\hline R-Square & 0,624535 & & \\
\hline Adjusted R-squared & 0,576261 & & \\
\hline S.E. of regression & 1,897570 & & \\
\hline F-statistic & $12,93726^{* * *}$ & & \\
\hline
\end{tabular}

\section{Sumber : Analisis data Primer}

Catatan : $* * *=$ Signifikansi pada tingkat kepercayaan $99 \%$

** = Signifikansi pada tingkat kepercayaan $95 \%$

* = Signifikansi pada tingkat kepercayaan $90 \%$

Dari hasil analisis tabel 3 tersebut terlihat bahwa variabel luas lahan, harga benih, harga pupuk urea, harga pupuk ponska, harga pestisda dan variabel varitas unggul memberikan pengaruh yang signifikan terhadap risiko pendapatan

\section{KESIMPULAN}

Pendapatan petani dipengaruhi oleh luas lahan, harga urea harga pupuk ponska, harga tenaga kerja dan dummy varitas. Peningkatan luas lahan, harga urea dan jenis varitas sejalan dengan peningkatan pendapatan. Sedangkan harga pupuk ponska dan harga tenaga kerja berpotensi menurunkan pendapatan petani padi.

Risiko pendapatan lahan sawah non irigasi lebih besar dari pada lahan sawah irigasi, yang ditunjukkan oleh koefisien variasi yang tinggi. 


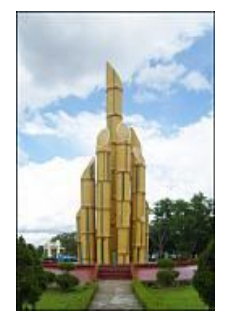

Maswadi, Dampak Penerapan Pungutan Ekspor Crude Palm Oil...

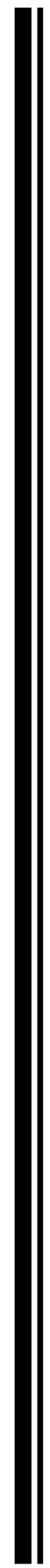

Nilai koefisien variasi yang tinggi menunjukkan risiko usahatani padi lahan non irigasi yang lebih besar dari sawah irigasi

Faktor luas lahan, harga urea, harga ponska, harga pestisida dan varitas berpengaruh nyata terhadap risiko pendapatan. Peningkatan luas lahan dan harga ponska akan menyebabkan peningkatan risiko pendapatan, sedangkan peningkatan harga urea, harga pestisida dan varitas menyebabkan penurunan risiko pendapatan.

\section{SARAN}

Untuk meningkatkan
pendapatan sekaligus
meminimumkan risiko usahatani
padi pada daerah irigasi
disarankan menanam varitas
unggul yang produktivitasnya
lebih tinggi dan diselingi dengan
penanaman varitas lokal yang
harga outputnya lebih tinggi.
Agar petani mampu melakukan
penanaman minimal 2 kali
setahun, maka perlu adanya
perbaikan sistem irigasi yang
selama ini menjadi kendala bagi
keberhasilan usahatani di
kabupaten Banjar

\section{DAFTAR PUSTAKA}

Assagaf, Djadid. 2004. Peluang Peningkatan Pendapatan Petani (analisis manfaat dan Biaya serta Risiko). Sekolah Pasca sarjana Institut Pertanaian Bogor
Badan Pusat Statistik. 2007. Kabupaten Banjar Dalam Angka. Martapura.

Gujarati, Damodar. N, 2006. Dasar-Dasar Ekonometrika Jilid II Edisi Ketiga. Penerbit Erlangga. Jakarta.

Hernanto, F. 1999. Ilmu Usahatani. Penebar Swadaya. Jakarta.

Kadarsan, Halimah.W,. 1992. Keuangan Pertanian Dan Pembiayaan Agribisnis. Gramedia Pustaka Utama. Jakarta.

Pappas, J.M dan Hirschey, Mark. 1995.

Ekonomi Manajerial Edisi Keenam Jilid II. Binarupa Akasara. Jakarta.

Senjawati, Nanik Dara. 2008. Analisis Risiko Usahatani Berbasis Padi di Kabupaten Kulon Progo. Desertasi Ekonomi Pertanian Sekolah Pasca Sarjana Universitas Gadjah Mada. Yogyakarta

Supriyati. Handewi, P. Salim. 2005. Diversifikasi Usahatani dan Tingkat Pendapatan Petani di Lahan sawah. Pusat Analisis sosial Ekonomi dan Kebijakan Pertanian. Bogor.

Supranto, J. 1983. Ekonometrika. Buku I dan II. BPFE. Jakartas

Surakhmad, W, 1988. Pengantar Penelitian Ilmiah, Dasar, Metode, Teknik. Tarsito. Bandung. 
Soekartawi, Rusmadi, Effi Damaijati. 1993. Risiko dan Ketidakpatian Dalam Agribisnis, Teori dan Aplikasi. Rajagrafindo Persada. Jakarta.

Soekartawi, Soeharjo.A, Dillon, J.A. 1986 . Ilmu Usahatani dan Penelitian Untuk Pengembangan Petani Kecil. UI Press. Jakarta.

Yotopoulus, P.A and J.B Nugent. 1979. Economics of Development Empirical Investigation. Harper and Row Publishers. New York.

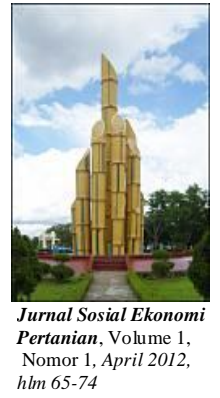

